\title{
Prepaid Metering System
}

\author{
Ms.Neha Choudhary ${ }^{1}$, Ms. Namrata Patil ${ }^{2}$, Ms.Snehal Chaudhari ${ }^{3}$, Mr.S.H.Rajput ${ }^{4}$ \\ BE (IT), Department of Information Technology, SSBT's COET Bambhori, Jalgaon (M.S.),India ${ }^{1,2,3}$ \\ Assistant Professor, Department of Information Technology, SSBT's COET Bambhori, Jalgaon (M.S.), India ${ }^{4}$
}

\begin{abstract}
In our India, there is lot of use of electricity in many different sectors and areas. This paper is based on prepaid system not postpaid as like existing system. First consumer pays for electricity and then use power for domestic and commercial purpose. Today's Energy Meter system is a complex and something headache process due to calculating and distributing bills. In Existing System, Meter readers have to go every home to home and take reading and paying bills is a post-paid system. To minimize complexity in calculating and distributing bills and misuse of electricity are the main purpose of this project .It is indirectly affect to avoid illegal activities like power theft.In our proposed system, there is use of GSM technology. With the help of GSM technology, consumer get warning alarm and messages on mobile about minimum amount and for next recharge. LCD shows total balance, remaining balance and used power.
\end{abstract}

Keywords: Energy Meter, Liquid Crystal Display (LCD), GSM.

\section{INTRODUCTION}

Large amount of electricity is use for various purposes like commercial, industrial and domestic use [1]. So to manage this record is very complex and hassle process.And the most important thing is large number of workers are [4].

needed for taking reading, calculating and distributing The monthly bill is provide to the consumer by workers billing process. In postpaid system, consumer pay bills after utilization of electricity at the end of every month. And the more complex process is for paying bills that consumer has to stand in a long queue. This takes more time. Existing system has more manual work but sometimes it is delayed because of bad weather conditions. Take reading is done by human so there is possibility of happening errors in his work.Overall process is very lengthy and tiresome process.

In PPM,consumer has installed digital meter and recharge it before electricity consumption.According to consumption credit deduct from their recharge and if balance is low then meter create warning alarm of low balance [2]. Prepaid Metering System represent energy meter to show consumption of energy.Prepaid means first consumer pay for electricity and then use power for domestic and commercial purpose. This system is helpful to reduce manual work.If the balance is null then the supply of electricity is cut off automatically with the help of relay.This system uses GSM technology that makes PPM wireless [3]. Due to this system every consumer use electricity carefully for its advantages.In this system consumer always conscious about its credit so they try to save maximum electricity and use carefully [4].

\section{EXISTING SYSTEM}

In Existing system, there is fitted electric meter system.Meter reader has to go at every home for take reading. If there is bad weather condition then it can trouble to go for take reading. Now a days the billing system is like a post paid system. The monthly bill is come at every home. The concept of Post paid system is first we use electricity and then pay the bill.This system is somewhat complex for calculating bills and distributing bills at door to door [4].At the time of taking reading step, by giving the money to the reader, consumer can reduce the number of units.so, in this way, corruption is occurred in Meter reading.And, this is one type of illegal activity

and then consumer has to stay in a long queue for paying bill.The major drawback of traditional billing system is power as well as energy theft. This existing system has get loss to the MSEB.This process is very tiresome and time consuming [5]. Mainly corruption is occurred in it.If the amount is not collect at counter in a given period of time then there will be extra charges for paying the bills.In this way,to avoid or reduce this drawbacks, we proposed PPM i.e. Prepaid Metering System which is based on the concept of First consumer pay for recharge and then he can use it. The advantage of this concept is to reduce the error made by human beings that are finding while taking reading. For convenience, remaining amount of energy display on LCD.This system help to avoid illegal activity that are done by the consumers. When the recharge amount is null then system will automatically shut down.

\section{PROPOSED SYSTEM}

Prepaid metering system installs a digital meter at every home, industry and offices. Prepaid metering system use smart card technology, in this project we first buy a credit from vending station and recharge our meter then according to balance consumer can use electricity and after utilization of electricity credit deducted from balance. There is some threshold value set for warning of low balance when balance equal to threshold value then create alarm it alert consumer for low balance and also send the message on mobile for next recharge. If credit reaches to zero then meter automatically shut down means cut off the power supply. Consumer has to go at vending station for recharge. This credit store into the GSM SIM which is inbuilt in meter. Recharge is done by mobile as we recharge our own mobile through vendor mobile. Consumer can recharge its SIM at any time in the month with the any amount. 


\section{International Journal of Advanced Research in Computer and Communication Engineering}

Vol. 4, Issue 3, March 2015

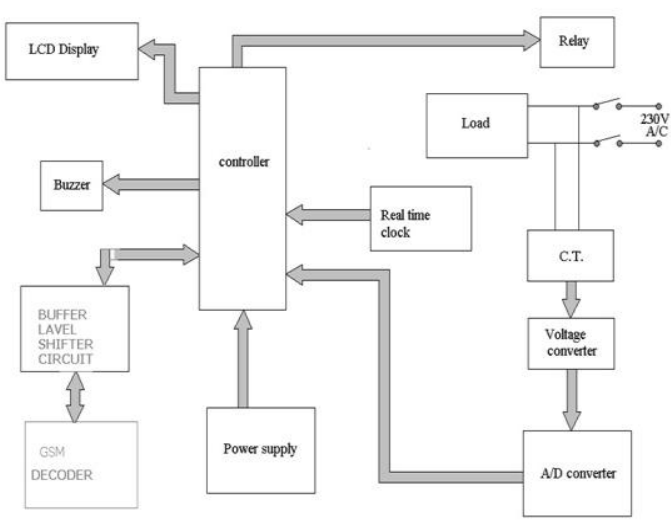

Fig.1 Block Diagram

In Prepaid metering system, consumer always conscious about its remaining credit and try to save maximum amount of electricity and use it carefully and avoid misuse.

In the Prepaid metering system there is very less interaction of human with the meter.So this system reduces the number of workers which is required for taking reading, calculating and distributing bill.

Because of less interaction of human there is no chance of corruption and misuse of electricity.

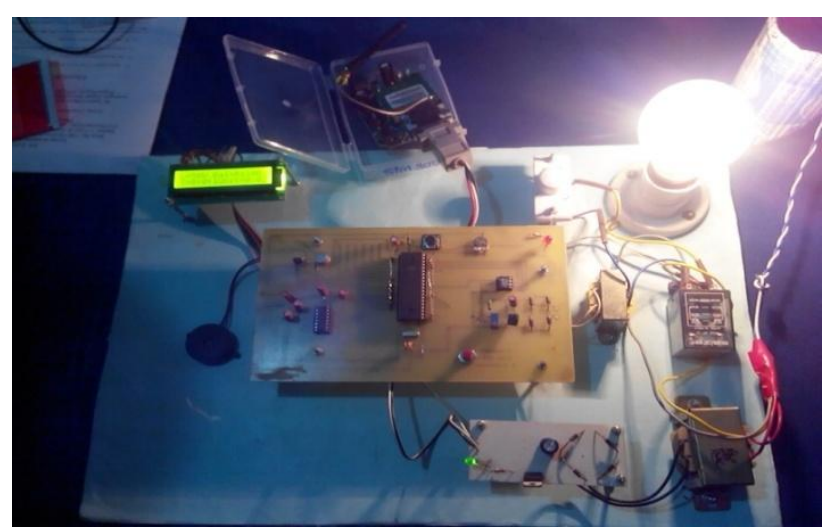

Fig. 2 circuit diagram 1

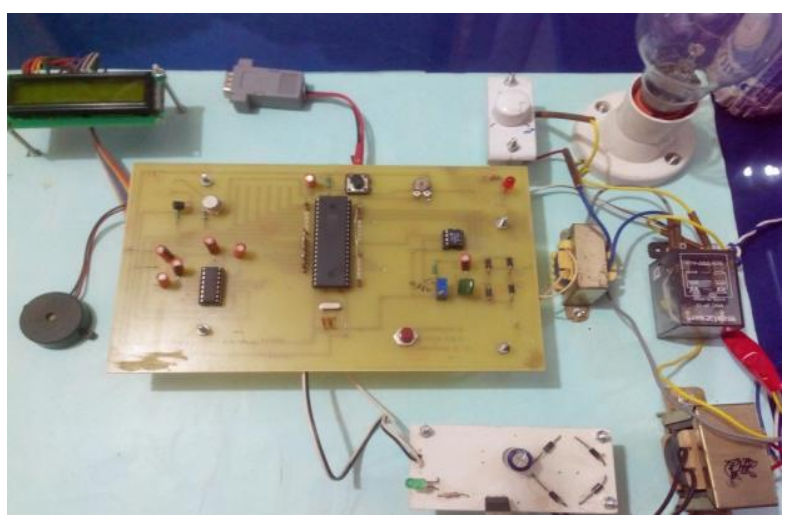

Fig. 3 circuit diagram 2
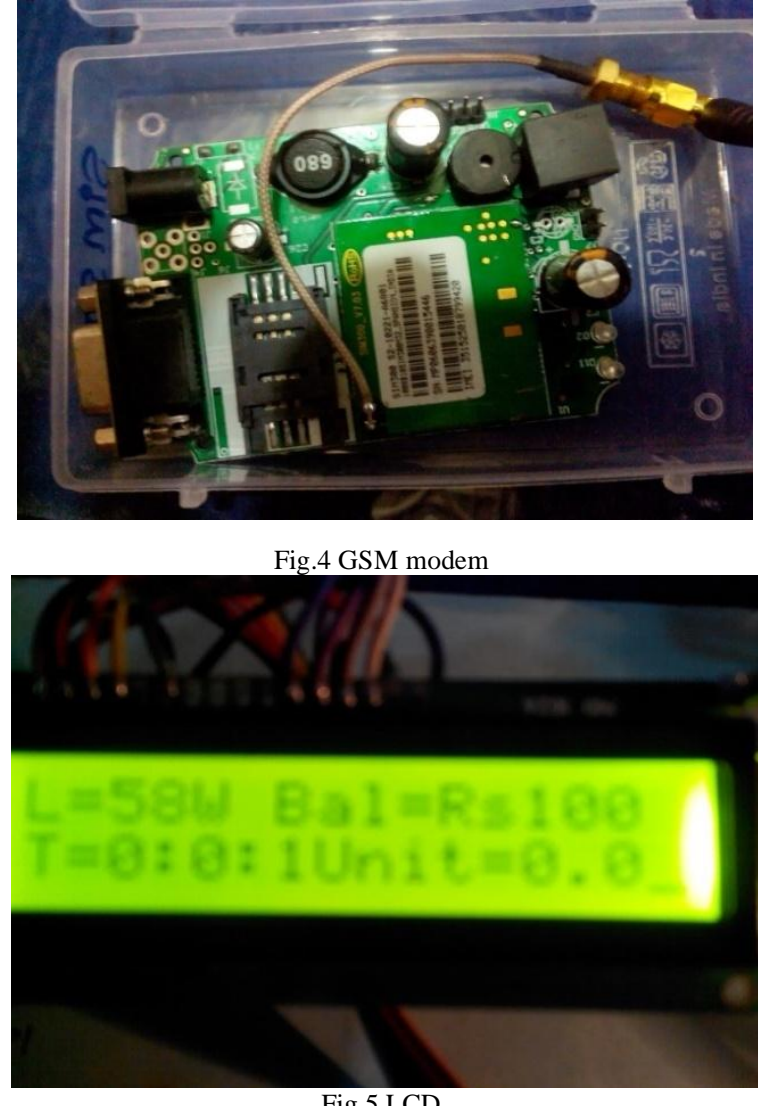

In this system we use the LCD which shows the reading like total balance,remaining balance and used power.It also consist of GSM modem which have one special slot for SIM which has a unique number,and consumer recharge that SIM through mobile

Following flow chart shows the sequence of Prepaid Metering System.

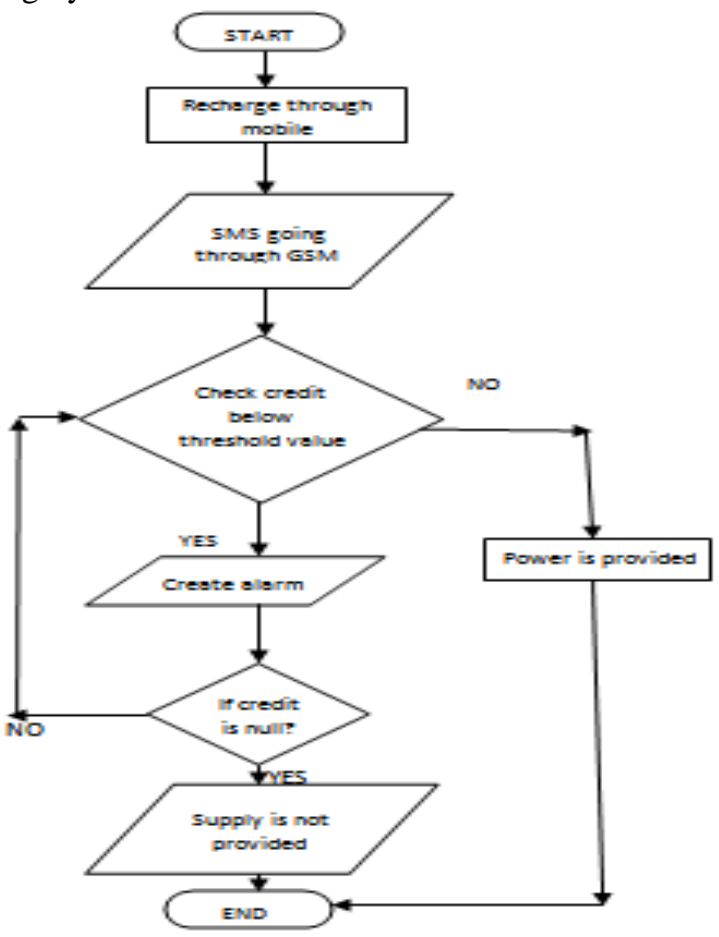

Flowchart: Prepaid Metering System 


\section{CONCLUSION}

Prepaid Metering System using electric meter using GSM fit into each home or industry. Based on the electricity utilization the credit will be deducted automatically from the recharge. As the balance goes under the threshold value, the meter gives warning icons and also sends the alert message on mobile through GSM. If credit reaches to zero the meter will automatically cut off the power supply. Prepaid Metering System minimizes the human intervention in taking reading, calculating and distributing bills which ultimately reduces many defects than the currently existing post paid billing systems. This is certainly beneficial to both consumers and power distribution companies.

\section{REFERENCES}

[1] Dr. K. Sheelasobanarani1, S. Dinesh Raja, B. Dhanaraj, K. Manickam, K. Karthick Raja, "A Prepaid Energy Meter for Efficient Power Management” International Journal of Emerging Technology and Advanced Engineering Website: www.ijetae.com (ISSN 2250-2459, ISO 9001:2008 Certified Journal, Volume 4, Issue 3, March 2014)

[2] Sapna Ganurkar, Pravesh Gour, "Prepaid Energy Meter for Billing System Using Microcontroller and Recharge Card" International Journal Of Core Engineering \& Management (IJCEM) Volume 1, Issue 1, April 2014.

[3] Jubi.K, Mareena John Department of Instrumentation and Control Engineering PSG College of Technology Peelamedu, Coimbatore, India,"Prepaid Energy Meter with GSM Technology", American International Journal of Research in Science, Technology, Engineering \& Mathematics

[4] Sudarshan K. Valluru Department of Electrical Engineering, Delhi Technological University "Design and Assemble of Low Cost Prepaid Smart Card Energy Meter - A Novel Design"International Journal on Electrical Engineering and Informa tics - Volume 6, Number 1 March 2014

[5] Md. Mejbaul Haque, Md. Kamal Hossain, Md. Mortuza Ali, Md. Rafiqul Islam Sheikh, "Microcontroller Based Single Phase Digital Prepaid Energy Meter for Improved Metering and Billing System" 1International Journal of Power Electronics and Drive System (IJPEDS) Vol.1, No.2, December 2011, pp. 139 147. 